\title{
EXPERIMENTAL INVESTIGATION ON STEEL-CONCRETE BOND STRENGTH IN SELF-COMPACTING CONCRETE
}

\author{
M. M. Kamal ${ }^{1}$, M. A. Safan ${ }^{1}$ and M. A. Al-Gazzar ${ }^{2}$ \\ ${ }^{1}$ Civil Engineering Dept., Faculty of Engineering, Minoufiya University, Egypt \\ ${ }^{2}$ Water Research Center, Ministry of Irrigation, Al-Kanater, Egypt
}

\begin{abstract}
The objective of this research was to evaluate the potentials of self-compacting concrete (SCC) mixes to develop bond strength. The investigated mixes incorporated relatively high contents of dolomite powder replacing Portland cement. Either silica fume or fly ash was used along with the dolomite powder in some mixes. Seven mixes were proportioned and cast without vibration in long beams with $10 \mathrm{~mm}$ and $16 \mathrm{~mm}$ steel dowels fixed vertically along the flowing path. The beams were then broken into discrete test specimens. A push-put configuration was adopted for conducting the bond test. The variation of the ultimate bond strength along the flowing path for the different mixes was evaluated. The steel-concrete bond adequacy was evaluated based on normalized bond strength. The results showed that the bond strength was reduced due to Portland cement replacement with dolomite powder. The addition of either silica fume or fly ash positively hindered further degradation as the dolomite powder content increased. However, all SCC mixes containing up to $30 \%$ dolomite powder still yielded bond strengths that were adequate for design purpose. The test results demonstrated inconsistent normalized bond strength in the case of the larger diameter compared to the smaller one.

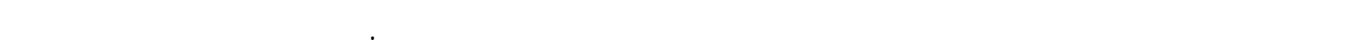

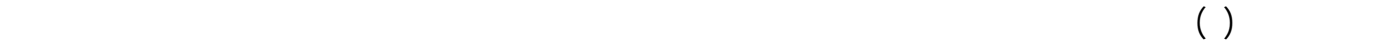

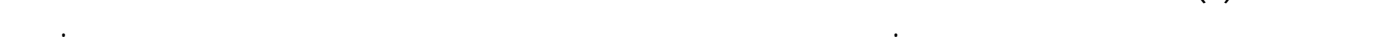

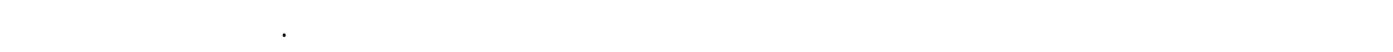

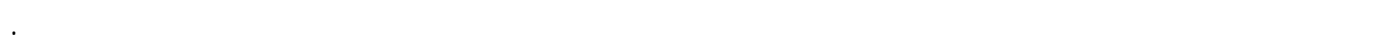

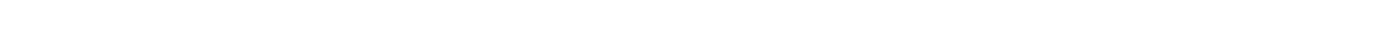

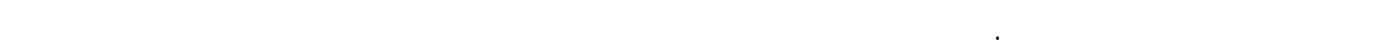

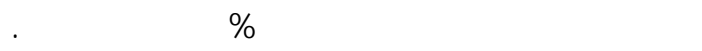

Keywords: Self-compacting concrete; bond; push-out; dolomite powder; silica fume; fly ash.

\section{INTRODUCTION}

Self-compacting concrete (SCC) refers to a normal or high strength concrete that is flowable enough to be placed without need for compaction due to the ability of filling the forms under gravity. Despite the high flowability of SCC, the mixes are sufficiently stable to resist segregation. Japanese researchers began developing the material in the 1980s to ensure high quality in concrete construction [1]. The availability of this type of concrete provided unique merits including faster construction rates since the concrete places so quickly, reduced labor since no vibration is needed, the quality of compaction is no longer relevant, good finished surface quality and design flexibility in detailing congested steel reinforcement with regard to the limited size of coarse aggregates and the passing ability of SCC [2]. Compared to conventional vibrated concrete (VC), SCC mixes typically use higher contents of fine materials and less coarse aggregate content. The maximum nominal size of the coarse aggregate is typically no more than $19 \mathrm{~mm}$. Also, the use of a high range water reducer is necessary to make the mix flowable at a reasonable water/cement ratio. Viscosity agents are sometimes used to make the mix robust and less sensitive to accidental variations in the proportions and/or quality of the used materials. Increasing the content of fine materials is typically achieved by the increased content of sand and other by-product materials that have specific potentials for being implemented in concrete manufacturing. Silica fume, fly ash, granulated blast furnace slag and limestone powders have been successfully implemented in both VC and SCC mixes. Pozzolanic activity, cementitious properties, smooth surface texture and fineness are 
appealing features that can be provided by these materials to improve the workability, strength and durability [3-5]. In addition, the consumption of byproduct materials has a positive impact on the environment and can also reduce the energy consumption in cement factories.

The authors have conducted extensive experimental testing to explore the potentials of lowcost SCC incorporating relatively high contents of dolomite powder. Early research was devoted to explore the productions aspects, the rheological properties and short term strength for single, binary and ternary systems of silica fume, fly ash and dolomite powders replacing Portland cement [6, 7]. Later, SCC mixes selected on compressive strength criterion were used to study the flexure and shear strength of reinforced concrete beams [8]. Also, these mixes were used to prepare reinforced concrete beams that were subjected to severe corrosive environment [9]. The results obtained that far were very encouraging for implementing binary systems of dolomite powder and either silica fume or fly ash to replace Portland cement in SCC mixes.

In the authors' previous works, dolomite powder (DP) rather limestone powder was used to replace Portland cement for two reasons. The first was the availability of the fine DP in local plants for readymix asphaltic concrete and the second was the restrictions of the Egyptian Code of Practice (ECP 203) [10] that did not allow the use of Portland limestone cements (PLC) in reinforced and prestressed concrete. While the code did not give an explanation for this restriction, a survey on the subject showed that the consulted international specifications were concerned about some durability considerations. For instant, the French Cement Standards in 1979 allowed the use of PLC containing up to $20 \%$ limestone as a lower cost cement for ordinary buildings not subject to sever exposure [11]. The British standard BS 5328-1 [12] restricted the use of PLC in reinforced concrete subjected to sever chloride exposure or freezing and thawing conditions, while its use was allowed in class 1 sulfate conditions $\left(\mathrm{SO}_{4}\right.$ concentration in the soil is less than $400 \mathrm{mg} / \mathrm{l})$. BS 8500 [13] reported that the BS 5328-1 durability restrictions were due to lack of information and stated, based on recent available data, that the performance of concrete made with PLC containing up to 20 percent limestone is equivalent to some other permitted cement types. However, BS 8500 in 2002 [13] still restricted the use of PLC in concrete exposed to sulfate bearing environment classified as DS- $1\left(\mathrm{SO}_{4}\right.$ concentration in the soil is less than $500 \mathrm{mg} / \mathrm{l}$ ). Later, a revision of BS 8500 in 2006 [13] adopted the changed guidance in BRE SD1 [14] and permitted using PLC in DS-2 sulfate conditions $\left(\mathrm{SO}_{4}\right.$ concentration in the soil 5001500 mg/l). Currently, BS EN 197-1 allows CEM II
Portland-composite cement to contain up to $35 \%$ limestone replacement levels. However, only CEM II/A-L and CEM II/A-LL containing 6-20\% limestone are allowed for use in DS-2 sulfate conditions according to BS 8500 in 2006 [13]. Recently in 2009, the Canadian Standards Association (CSA) standard (CSA A23.1) [15] permitted the use of PLC containing up to $15 \%$ limestone in all classes of concrete except sulfateexposure classes. Hotton et al. [16] and Thomas et al. [17] reported that PLCs were the largest single type of cement currently used in the European countries in a variety of works including pavement works and precast concrete. They reported that the benefits of PLCs included: reduced greenhouse gas emissions due to reduced $\mathrm{CO}_{2}$ as the clinker factor in the cement is reduced, improved workability and pumpability, similar physical performance to current cements when the cements are properly optimized and similar durability to chloride ingress and alkali silica reaction.

The current work was devoted to study the bond strength between steel bars and concrete utilizing test specimens prepared using the SCC mixes tested in previous research work by the authors. Steel-concrete bond is a fundamental property to ensure the integrity of reinforced concrete structural elements because efficient bond ensures reliable force transfer between reinforcement and the surrounding concrete. In case of a deformed steel bar, the following mechanisms contribute to force transfer: (1) Chemical adhesion between the bar and the concrete, (2) Frictional forces arising from the roughness of the interface and (3) Mechanical anchorage or bearing of the ribs against the concrete surface. It has been demonstrated that the bond strength is governed by the mechanical properties of the concrete, the volume of the concrete around the bars in terms of the concrete cover and bar spacing parameters; the presence of confinement in the form of transverse reinforcement, which can delay and control crack propagation; and the diameter and geometry of the bar (deformation height, spacing and face angle) [18, 19].

There were only limited researches on bond strength in SCC providing conclusions that were not comparable. In the bond tests carried out using pullout specimens, De Almeida et al. [20] obtained similar bond strengths with SCC and VC, Chan et al. [21] and Daoud et al. [22] obtained 5\% higher strengths with SCC, while Zhu et al. [23] reported strengths that were up to $25 \%$ higher with SCC, with lower bond stresses as the bar size increased. Turk et al. [24] studied the effect of using different types and contents of fly ash and silica fume on the bond strength using splice specimens in different SCC and $\mathrm{VC}$ mixes. The results showed that SCC demonstrated higher bond strengths compared to $\mathrm{VC}$ 
due to superior filling and covering capability. Moreover, the beam specimens produced from SCC containing $5 \%$ replacement of silica fume had the greatest stiffness as a result of the pore structure improvement due to the pozzolanic activity of silica fume.

\section{BOND TEST SPECIMENS}

A variety of test specimen configurations have been used to study bond between reinforcing bars and concrete. The details of the specimen affect both the measured bond strength as well as the nature of the bond response. According to the ACI 408R-03 report [18], the four most common configurations are the pull-out specimen, beam end specimen, beam anchorage specimen and splice specimen. Pull-out specimens are widely used because of ease of fabrication. However, they are considered to be less realistic because the stress fields within the specimen simulate few cases in actual construction. As the bar is placed in tension, the concrete is placed in compression. Further, compressive struts form between the support points for the concrete and the surface of the reinforcing bar, placing the bar surface in compression. On the other hand, beam anchorage and splice specimens represent larger scale specimens designed to directly measure development and splice strengths in full-size members. The anchorage specimen simulates a member with a flexural crack and a known bonded length. The splice specimen, normally fabricated with the splice in a constant moment region, is easier to fabricate and produces similar bond strengths to those obtained from the anchorage specimen.

\section{RESEARCH SIGNIFICANCE}

This research was a part of an extensive program to explore the potentials of low-cost self-compacting concrete. Earlier, the production aspects, rheology and short-term compressive strength were investigated for SCC mixes incorporating different systems of by-product fillers. Also, the shear strength in $\mathrm{RC}$ beams and the performance of $\mathrm{RC}$ beams in an aggressive environment were investigated for selected mixes that demonstrated relatively superior strength performance. The current work was devoted to explore the bond strength between steel bars and SCC. The main parameters were the diameter of the steel bars, composition of the filler material and variation of compressive strength along the flow path of SCC. The research presents correlations between the experimental bond strength and compressive strength to asses the capability of the different mixes to develop adequate levels of bond strength. Actually, the bond strength is strongly influenced by the adhesion characteristics and the mechanical prosperities of the surrounding concrete. The current research results are expected to provide some necessary answers concerning the bond strength as an essential prosperity for the integrity of structural elements with regard to the variable composition of SCC among the other mentioned test parameters.

\section{MATERIALS}

Cement and fillers: cement type CEM I $32.5 \mathrm{~N}$ meeting the requirements of BS EN 197-1:2000 [25] was used. The specific gravity of cement was 3.13 and the initial setting time was $90 \mathrm{~min}$. at 27.5 percent water for standard consistency. Locally produced densified silica fume was delivered in 20 $\mathrm{kg}$ sacks. According to the manufacturer, the lightgray powder had a specific gravity of 2.2 , specific surface area of $17 \mathrm{~m}^{2} / \mathrm{gm}$, loss on ignition of 1.5 , and $\mathrm{SiO}_{2}$ content of 93 percent. Imported class $\mathrm{F}$ fly ash meeting the requirements of ASTM C618 [26] was used. According to the manufacturer, the average sum of $\mathrm{SiO}_{2}, \mathrm{Al}_{2} \mathrm{O}_{3}$ and $\mathrm{Fe}_{2} \mathrm{O}_{3}$ is 85 percent by weight with a specific gravity of 2.1 , and loss on ignition of 1.25 percent. The particle size distribution curve, Fig. (1), shows that 90 percent by weight of ash passes through the $45 \mu \mathrm{m}$ sieve. The dolomite powder was obtained as a by-product from a local plant for ready-mix asphaltic concrete. The production processes include drying the crushed dolomite used as a coarse aggregate by heating at a degree of $120{ }^{\circ} \mathrm{C}$ and sieving the aggregates to separate the different sizes. A small fraction of the powder that passes through sieve No. $50(300 \mu \mathrm{m})$ is used in the mix, while most of the powder is a byproduct. This powder had a light brownish color, specific gravity of 2.72. Sieving six random samples of the powder showed that the average passing percentage through the $45 \mu \mathrm{m}$ sieve was 63 percent. The chemical analysis results of the fine materials are reported in Table (1). Fig. (1) shows the grading of the used fine materials.

$\underline{\text { Table 1. Chemical analysis of fine materials (\% by mass) }}$

\begin{tabular}{ccccc}
\hline Material & cement & $\begin{array}{c}\text { silica } \\
\text { fume }\end{array}$ & $\begin{array}{c}\text { fly } \\
\text { ash }\end{array}$ & $\begin{array}{c}\text { Dolomite } \\
\text { Powder }\end{array}$ \\
\hline $\mathrm{SiO}_{2}$ & 24.3 & 93.2 & 49.0 & 0.83 \\
$\mathrm{Fe}_{2} \mathrm{O}_{3}$ & 3.67 & 1.58 & 4.10 & 0.52 \\
$\mathrm{Al}_{2} \mathrm{O}_{3}$ & 4.10 & 0.51 & 32.3 & 0.77 \\
$\mathrm{CaO}$ & 58.3 & 0.20 & 5.33 & 28.5 \\
$\mathrm{MgO}$ & 2.35 & 0.57 & 1.56 & 19.3 \\
$\mathrm{~K}_{2} \mathrm{O}$ & 0.98 & 0.53 & 0.54 & nd \\
$\mathrm{Na}_{2} \mathrm{O}$ & 0.35 & 0.45 & 0.28 & nd \\
$\mathrm{SO}_{3}$ & 3.40 & 0.22 & 0.16 & nd \\
$\mathrm{CO}_{2}$ & $\mathrm{Nd}$ & nd & $\mathbf{0 . 8 0}$ & 46.8 \\
$\mathrm{L.O.I}$ & 2.10 & 2.62 & 1.25 & 43.2 \\
\hline nd: not detected & & & &
\end{tabular}

Aggregates: natural siliceous sand having a fineness modulus of 2.54 and a specific gravity of 2.65 was used. Crushed dolomite with a maximum nominal size of $16 \mathrm{~mm}$ was used as coarse aggregate. The aggregate had a specific gravity of 2.65 and a crushing modulus of 23 percent. About half of the 
particles were flaky and elongated. The grading of the used aggregates is shown in Fig. (1).

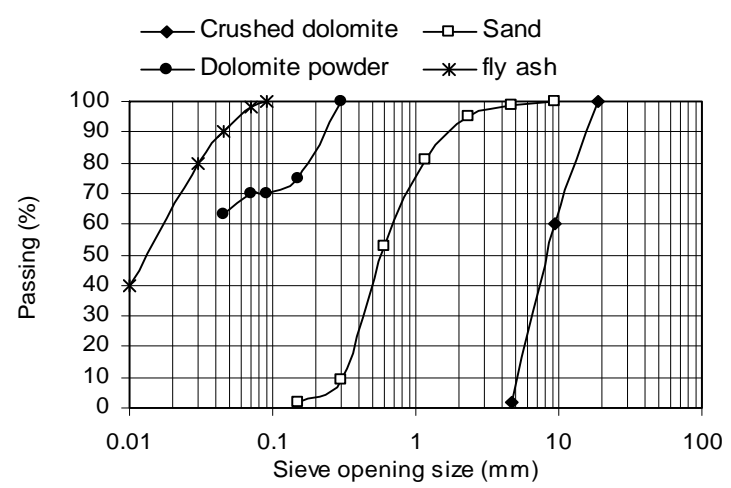

Figure 1. Particle size distribution for concrete materials

Admixtures: a traditional sulfonated naphthalene formaldehyde condensate HRWR admixture conforming to ASTM C494 (types A and F) [27] was used. The admixture is a brown liquid with a specific gravity of 1.18 .

Steel dowels: high tensile ribbed steel bars of $10 \mathrm{~mm}$ and $16 \mathrm{~mm}$ diameter were cut into $180 \mathrm{~mm}$ and 240 $\mathrm{mm}$ long dowels, respectively. The geometry of the bars and measured dimensions are shown in Table (2) and Fig. (2).

Table 2. Dimensions of the steel bar profile

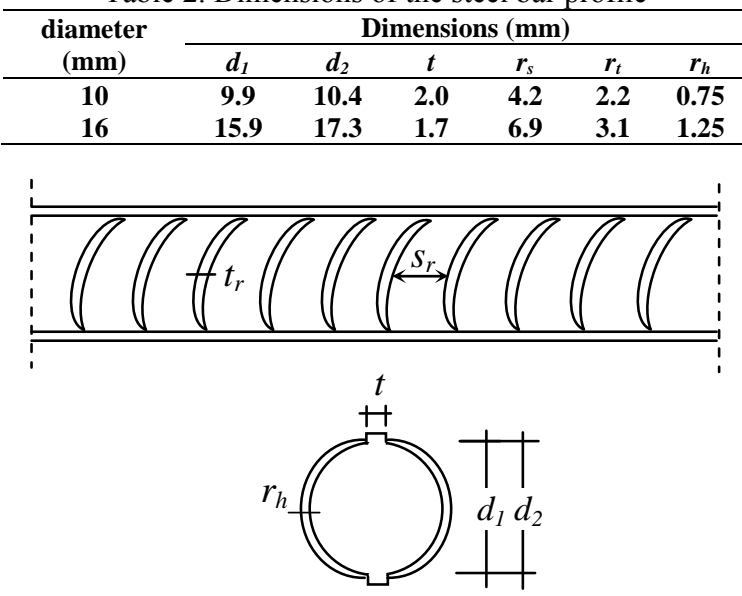

Figure 2. Geometry of the steel bars

\subsection{Concrete mix proportions}

Based on the results reported in an initial phase of research [6], seven mixes were selected to produce SCC based on compressive strength criterion. The selected mixes incorporated dolomite powder (DP) replacing up to $30 \%$ of cement weight along with either silica fume (SF) or fly ash (FA) that replaced $10 \%$ of cement by weight. The constituents of the selected SCC mixes are given in Table (3). In these mixes, the fine-to-coarse aggregate ratio was 1.13 , the total content of powders (cement and fillers) was
$500 \mathrm{~kg} / \mathrm{m}^{3}$, the HRWR dosage was fixed at $10 \mathrm{~kg} / \mathrm{m}^{3}$ ( $2 \%$ by weight of powders). The water content was determined by trail and error procedure to obtain consistent mixes with the required fresh rheological properties. Table (4) shows the mechanical properties at 28 days, and the measured rheological properties.

Table 3. Concrete mix materials and proportions

\begin{tabular}{cccccccc}
\hline \multirow{2}{*}{ Mix } & \multicolumn{7}{c}{ Mix Constituents ${ }^{*}, \mathbf{k g} / \mathbf{m}^{3}$} \\
\cline { 2 - 8 } & C & FA & CA & w & DP & SF & FA \\
\hline M1 & $\mathbf{5 0 0}$ & $\mathbf{9 4 5}$ & $\mathbf{8 4 0}$ & $\mathbf{1 6 0}$ & - & -- & -- \\
M2 & $\mathbf{4 5 0}$ & $\mathbf{9 3 5}$ & $\mathbf{8 3 0}$ & $\mathbf{1 6 5}$ & $\mathbf{5 0}$ & - & -- \\
M3 & $\mathbf{4 0 0}$ & $\mathbf{9 2 5}$ & $\mathbf{8 2 0}$ & $\mathbf{1 7 0}$ & $\mathbf{1 0 0}$ & -- & -- \\
M4 & $\mathbf{3 5 0}$ & $\mathbf{9 1 5}$ & $\mathbf{8 1 0}$ & $\mathbf{1 7 0}$ & $\mathbf{1 0 0}$ & $\mathbf{5 0}$ & -- \\
M5 & $\mathbf{3 0 0}$ & $\mathbf{9 0 0}$ & $\mathbf{8 0 0}$ & $\mathbf{1 7 5}$ & $\mathbf{1 5 0}$ & $\mathbf{5 0}$ & -- \\
M6 & $\mathbf{3 5 0}$ & $\mathbf{9 1 5}$ & $\mathbf{8 1 0}$ & $\mathbf{1 7 0}$ & $\mathbf{1 0 0}$ & -- & $\mathbf{5 0}$ \\
M7 & $\mathbf{3 0 0}$ & $\mathbf{9 0 0}$ & $\mathbf{8 0 0}$ & $\mathbf{1 7 5}$ & $\mathbf{1 5 0}$ & -- & $\mathbf{5 0}$ \\
\hline "superplasticizer dosage in all mixes $=\mathbf{1 0 ~} \mathbf{~ k g ~ / \mathbf { m } ^ { 3 }}$
\end{tabular}

Table 4. Rheological and hardened properties

\begin{tabular}{|c|c|c|c|c|c|}
\hline \multirow{2}{*}{ Mix } & \multicolumn{3}{|c|}{ mechanical properties } & \multicolumn{2}{|c|}{$\begin{array}{l}\text { Rheological } \\
\text { properties }\end{array}$} \\
\hline & $\begin{array}{c}f_{c u} \\
(\mathrm{MPa})\end{array}$ & $\begin{array}{c}f_{r} \\
(\mathrm{MPa})\end{array}$ & $\begin{array}{c}f_{r} / \\
f_{c u}^{0.5}\end{array}$ & $\begin{array}{c}\text { slump } \\
\text { flow } \\
(\mathrm{mm})\end{array}$ & $\begin{array}{c}\text { V-funnel } \\
t_{0} \text { (sec.) }\end{array}$ \\
\hline M1 & 34.0 & 3.8 & 0.65 & 700 & 6.0 \\
\hline M2 & 33.0 & 4.0 & 0.69 & 665 & 6.4 \\
\hline M3 & 29.5 & 3.8 & 0.70 & 655 & 5.5 \\
\hline M4 & 35.0 & 4.1 & 0.69 & 600 & 5.5 \\
\hline M5 & 31.5 & 3.9 & 0.69 & 580 & 5.2 \\
\hline M6 & 30.5 & 4.0 & 0.72 & 650 & 5.0 \\
\hline M7 & 28.5 & 3.9 & 0.73 & 640 & 5.1 \\
\hline
\end{tabular}
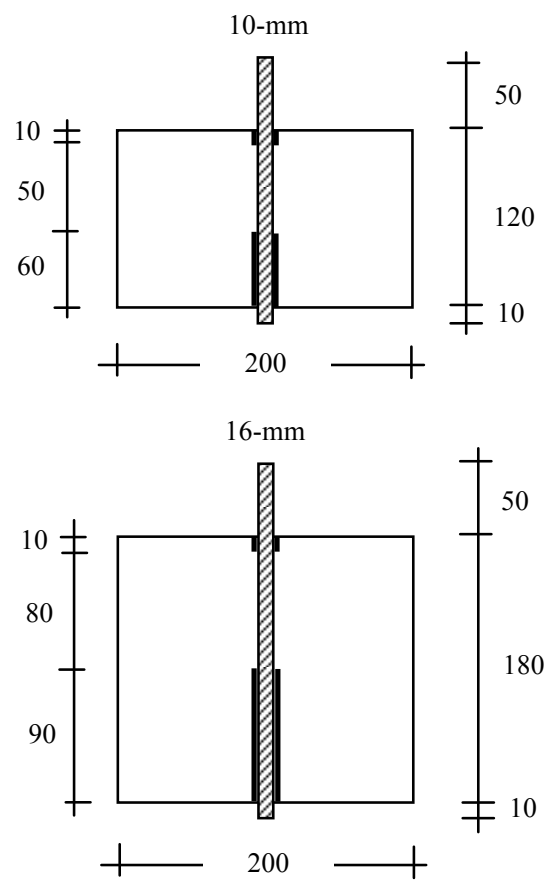

Figure 3. Configuration of push-out bond test specimens 

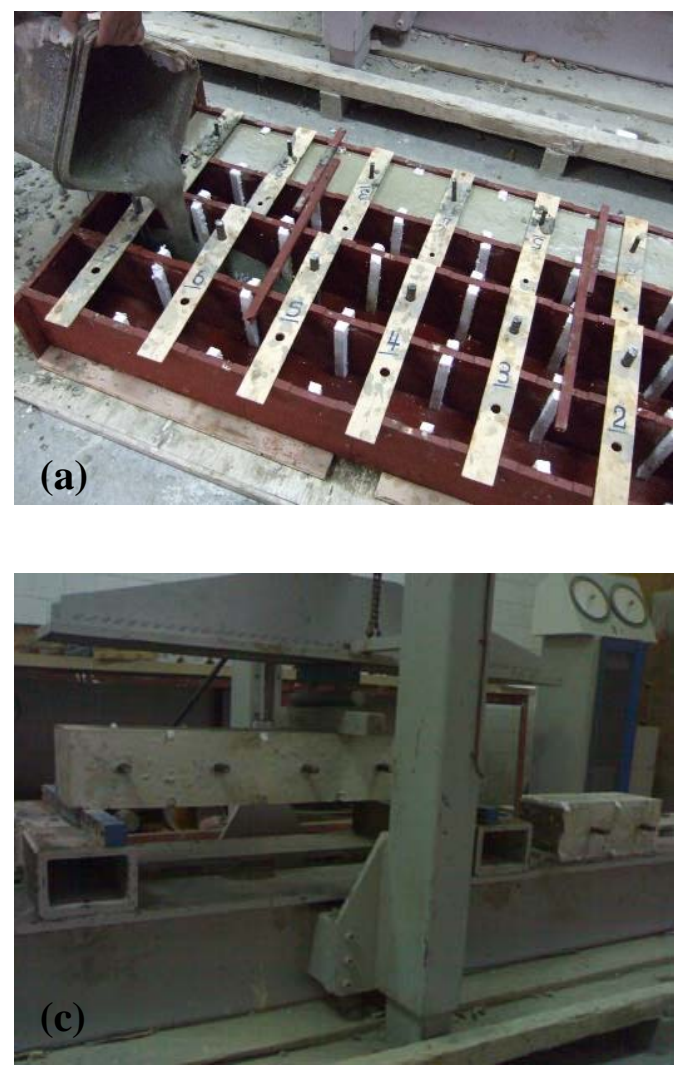
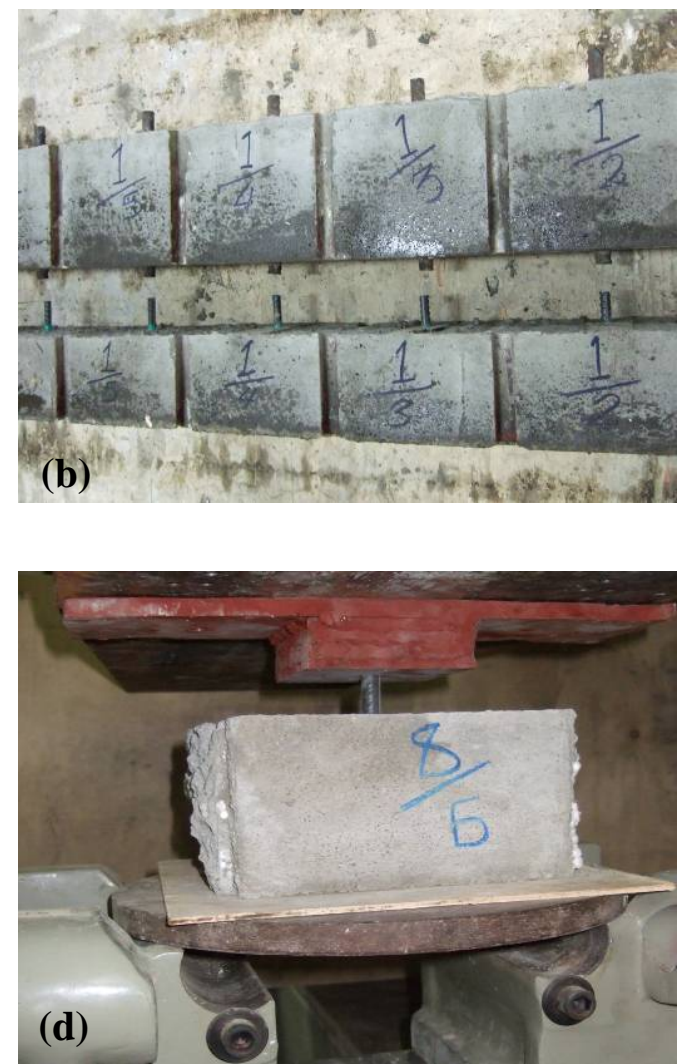

Figure 4. Preparation and testing of push-out test specimens

\subsection{Configuration of push-out specimens}

Push-out test specimens were used in the current work. Generally, the weak points of push-out test specimens, similar to pull-out test specimens, were the friction between the specimen and the bearing plate, and the arch-effect in the region close to the bearing plate. For these reasons, the bonded length was moved away from the bearing plate by providing a broken- bond zone next to the bearing plate as can be seen in Fig. (3). The procedure adopted by Foroughi et al. [28] to introduce a broken-bond zone and to avoid an unplanned force transfer between the bar and the concrete in this area was followed by encasing the bar with a plastic tube and sealing with a highly elastic silicone material. Also, $10 \mathrm{~mm}$ broken-bond zone was provided at the loading end so that the bonded length was five times the bar diameter in both the $10 \mathrm{~mm}$ and $16 \mathrm{~mm}$ bar specimens.

\subsection{Casting forms:}

Casting forms were needed to manufacture concrete beams by casting the SCC mixes at one end and allowing concrete to flow to the other end without any compaction or vibration. The forms were designed to make it possible to split each beam into seven bond specimens with a steel dowel inserted at the center of each specimen. Specially designed wooden forms were manufactured for this purpose. The wooden forms had net internal dimensions of $120 \mathrm{~mm}$ depth, $150 \mathrm{~mm}$ width and $1400 \mathrm{~mm}$ length for the $10 \mathrm{~mm}$ steel bar diameter specimens. The corresponding dimensions for the $16 \mathrm{~mm}$ steel bar diameter specimens were $180 \mathrm{~mm}, 150 \mathrm{~mm}$ and 1400 $\mathrm{mm}$. A separate plate was laid along the bottom of the form. The bottom plate was provided with seven holes at $200 \mathrm{~mm}$ center-to-center spacing to accommodate the lower end of the steel dowel. Vertical $25 \times 25 \mathrm{~mm}$ polyurethane strips were cut and adhered along the depth of the two sides of the form at $200 \mathrm{~mm}$ center-to-center spacing. The soft polyurethane strips were intended to provide notches along the beam specimens to facilitate its splitting into discrete test specimens. After sampling the forms, a thin layer of grease was applied to the internal faces to prevent water absorption and ensure easy stripping of the forms. Upper horizontal plywood strips provided with holes were used to confine the upper portion of the steel dowel and thus the dowels were held in a vertical position during casting. Fig. (4-a) shows the wooden forms with the steel dowels inserted and confined.

Two 40-liter batches were used to cast two beams of $120 \mathrm{~mm}$ and $180 \mathrm{~mm}$ depth along with one 100 $\mathrm{mm}$ cube to determine the compressive strength, $f_{c u}$, and one $100 \times 100 \times 500 \mathrm{~mm}$ prism to determine the 
tensile strength in terms of the fracture modulus, $f_{r}$. Each concrete mix was used to fill the forms and molds three times, so that each reported test result was the average of three test results. After mixing, the concrete was poured in a wide vessel and successively hand-poured in the forms and molds, Fig. (4-a). The forms were stripped 24 hours after casting. Fig. (4-b) shows the beam specimens after stripping and sequentially numbering the bond test specimens. After that, each beam was carefully poisoned in a hydraulic flexure machine to split it at the notched sections and obtain the bond test specimens, Fig. (4-c). All specimens were cured under continuously wet cloth that was moistened twice a day until testing at 28-day age.

\subsection{Testing procedure}

A total number of 147 bond test specimens, 21 cubes and 21 prisms were tested. Fig. (4-d) shows the test set up and loading configuration of the push-out test. The bond test specimen was tested under a compression force driving down the steel dowel. A $500 \mathrm{kN}$ universal testing machine was used to apply the compression force at a loading rate of $50 \mathrm{kN} / \mathrm{min}$. The machine provided an automatic control of the loading range to ensure precise load measurements. A $20 \mathrm{~mm}$ thick bearing plate provided with a central hole was used to support the test specimen. The plate was supported on the edges of a rigid base allowing the penetration of the dowel. A packing plywood plate was used to ensure even contact between the bottom surface of the concrete specimen and the bearing plate. To prevent buckling of the $50 \mathrm{~mm}$ long upper free part of the dowel under the applied load and to ensure eccentric loading, a special steel punched head was fixed in the upper platen of the testing machine. The punched head confined $30 \mathrm{~mm}$ of the free loaded part and thus a bar length of 20 $\mathrm{mm}$ was available for the dowel to penetrate through the concrete block. The $20 \mathrm{~mm}$ maximum penetration value was more than sufficient to achieve the ultimate bond strength knowing that the rip spacing was $4.2 \mathrm{~mm}$ in case of the $10-\mathrm{mm}$ dowels and 6.9 $\mathrm{mm}$ in case of the $16 \mathrm{~mm}$ dowels. The test was ended once the ultimate load was recorded.

\section{ANALYSIS OF TEST RESULTS}

While the configuration of the push-out test specimen adopted in this work is not a standard one, some measures were considered to make the obtained results more realistic. The bonded length was shifted away from the bearing plate to avoid confinement effect due to the lateral compression stress induced in the concrete. Also, a relatively limited bond length of five times the steel bar size was adopted. These factors were expected to yield favorable bond failures due to the slip of the bar rather than due to splitting of concrete. However, splitting failures could still occur if the tensile strength is exhausted given that no radial steel reinforcement was provided to resist splitting.

The test results were evaluated based on normalized bond strength obtained by dividing the average bond strength of a given mix to the square root of the corresponding compressive strength. The bond strength was calculated by relating the ultimate load by the bonded area ( $\pi$.d.l). Given that the bonded length $(l)$ was five times the bar diameter $(d)$, the ultimate bond strength can be expressed as:

$f_{b}=P_{u} / 5 \pi d^{2}$

Due to the variation of the concrete compressive strength, the bond strength was expressed in terms of normalized bond strength $f_{b n}$, where:

$f_{b n}=f_{b} / f_{c y}^{0.5}$

To examine the adequacy of the obtained levels of bond strength, two approaches were adopted. The first was to checkout the design bond strength requirements in the ACI 318-08 code [29] and the second was to compare the obtained results with the results available in the literature for similar SCC mixes and bar diameters. For this purpose, the bond strength was related to the square root of the cylinder compressive strength. The cylinder compressive strength $f_{c y}$ was taken equal to $80 \%$ of the corresponding cube compressive strength according to data collected by Domone [30]. The average bond strength along the flowing path, the total average and the normalized bond strength are reported in Tables $(5,6)$.

Table 5. Bond strength [10-mm bar specimens] (MPa)

\begin{tabular}{cccccccc}
\hline Spec. & \multicolumn{7}{c}{ Mix No. } \\
\cline { 2 - 8 } No. & 1 & 2 & 3 & 4 & 5 & 6 & 7 \\
\hline 1 & 13.1 & 9.4 & 5.3 & 6.8 & 5.5 & 5.6 & 4.9 \\
2 & 15.4 & 9.8 & 5.5 & 6.9 & 6.0 & 6.0 & 6.2 \\
3 & 15.9 & 12.4 & 6.9 & 7.8 & 6.4 & 6.8 & 6.6 \\
4 & 17.8 & 10.2 & 6.6 & 7.5 & 7.4 & 7.2 & 7.3 \\
5 & 18.7 & 10.2 & 6.0 & 7.2 & 8.1 & 6.6 & 6.1 \\
6 & 17.1 & 9.7 & 6.0 & 6.9 & 6.8 & 6.4 & 4.9 \\
7 & 16.8 & 9.2 & 5.0 & 6.5 & 6.3 & 6.3 & 4.5 \\
\hline Aver. & 16.4 & 10.1 & 5.9 & 7.1 & 6.6 & 6.4 & 5.8 \\
\hline$f_{b n}$ & 3.1 & 2.0 & 1.2 & 1.3 & 1.3 & 1.3 & 1.2 \\
\hline & & & & & & &
\end{tabular}

Table 6. Bond strength [16-mm bar specimens] (MPa)

\begin{tabular}{cccccccc}
\hline Spec. & \multicolumn{7}{c}{ Mix No. } \\
\cline { 2 - 8 } No. & 1 & 2 & 3 & 4 & 5 & 6 & 7 \\
\hline 1 & 11.3 & 8.7 & 5.6 & 7.6 & 6.4 & 6.4 & 10.0 \\
2 & 11.1 & 9.3 & 5.8 & 7.7 & 6.9 & 6.7 & 9.3 \\
3 & 12.9 & 9.8 & 6.9 & 7.9 & 6.7 & 7.3 & 9.3 \\
4 & 12.4 & 9.1 & 6.0 & 7.8 & 7.1 & 7.6 & 10.4 \\
5 & 13.1 & 8.4 & 6.0 & 8.0 & 6.7 & 8.0 & 8.7 \\
6 & 12.0 & 8.4 & 5.8 & 8.0 & 6.2 & 7.6 & 8.4 \\
7 & 11.8 & 8.2 & 5.3 & 7.6 & 6.2 & 6.7 & 8.4 \\
\hline Aver. & 12.1 & 8.9 & 5.9 & 7.8 & 6.6 & 7.2 & 9.2 \\
\hline$f_{b n}$ & 2.3 & 1.7 & 1.2 & 1.5 & 1.3 & 1.5 & 1.9 \\
\hline
\end{tabular}


The current ACI 318-08 code [29] did not provide an explicit expression linking the bond strength to the concrete compressive strength. Rather, the bond strength was implicitly applied in the calculation of the development length. The development length concept is based on the average bond stress over the length of embedment of the reinforcement. For some favorable conditions concerning the spacing between developed or spliced bars, clear cover and confinement, the following equation is used to calculate the development or splice length $(l)$ associated with relatively higher bond strengths for $19 \mathrm{~mm}$ and smaller steel bars:

$l=f_{y} d / 2.1 f_{c y}^{0.5}$

Setting the ultimate force in the push-out bond test equal to $f_{y} A_{b}$, then the bond strength $\left(f_{b}\right)$ can be expressed as:

$f_{b}=f_{y} A_{b} / \pi d l$

where $f_{y}$ is the yield stress of steel and $A_{b}$ is the area of the steel bar. Equation (4) yields:

$l=f_{y} d / 4 f_{b}$

The analogy between equations (3) and (5) yields:

$f_{b}=0.53 f_{c y}^{0.5}$

Equation (6) shows that the normalized bond strength for design purposes is taken 0.53 in favorable design conditions that require the development of satisfactory bond strength levels. The normalized bond strength values in Tables $(5,6)$ ranged from 1.21 to 1.97 for the SCC mixes incorporating dolomite powder. These values are 2.3 to 3.7 times the design value with an average of 2.6 and 2.9 for the $10 \mathrm{~mm}$ and $16 \mathrm{~mm}$ bars, respectively.

Fig. (5) shows a plot of the normalized bond strength obtained from pull-out tests against the corresponding compressive strength $\left(f_{c y}\right)$. The data were collected for different SCC mixes that had comparable compressive strength in the range of 26 to $36 \mathrm{MPa}$ and steel bar diameters of 10,14 and 16 $\mathrm{mm}[28,30,31]$. In this range, the normalized bond strength varied from 1.07 to 2.6. It can be seen that the obtained normalized bond strengths are within this range.

The $10 \mathrm{~mm}$ and $16 \mathrm{~mm}$ test specimens cast using mixes 1 and 2 failed due to splitting as the tensile stresses reached its ultimate values. The average normalized bond strength was higher in the $10 \mathrm{~mm}$ bar diameter specimens compared to the $16 \mathrm{~mm}$ diameter specimens. The decrease of the bond strength for a given concrete strength as the steel bar diameter increased has been traditionally reported in

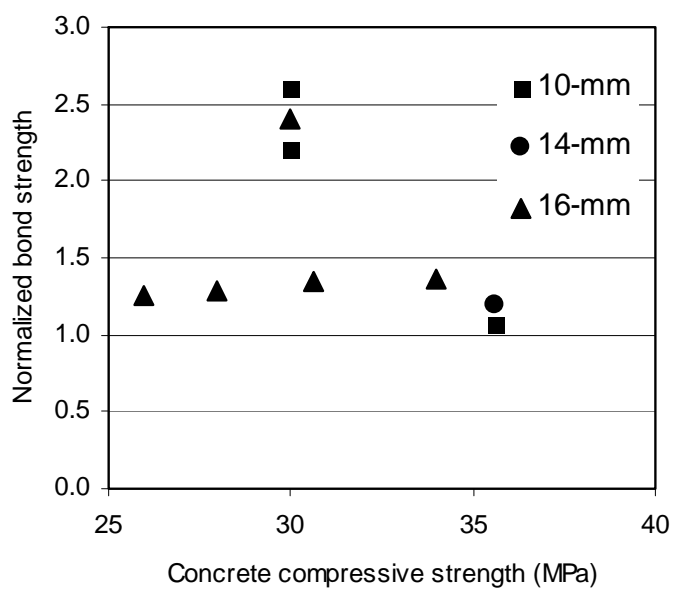

Figure 5. Normalized bond strength and corresponding compressive strength

the literature. The rest of the test specimens failed favorably due to the penetration of the steel par through the concrete without concrete cracking. This behavior can be attributed partially due to the relative improvement of the tensile strength expressed in terms of the normalized values of the fracture modulus as indicated in Table (4). On the other hand, SCC mixes incorporating finely divided minerals were reported to demonstrate improved interfacial transition zones between the paste and the steel bars. Zhu et al. [23] investigated the steel-concrete interfacial transition zone with a nano-indentation technique, and found that the increased bond strength with the SCC mixes compared to vibrated concrete could be attributed to a greater uniformity in the ITZ around the bars. The relative improvement of the tensile strength and uniformity of the ITZ associated with better adhesion can rationally explain the penetration of the steel bar extracting a uniform layer of mortar between the ribs as observed after the test. This failure mode was associated with two distinct observations. First, the reduction of the both the bond and normalized bond strength due to cement replacement in all mixes. Second, the normalized bond strength was higher for the $16 \mathrm{~mm}$ bars in mixes 4, 6 and 7 compared to the $10 \mathrm{~mm}$ bars, while the normalized bond strength was the same for the two diameters in mixes 3 and 5. The reduction of the bond strength in SCC mixes seemed to increase as the percentage replacement with dolomite powder (DP) increased in mix 3 compared to mix 2. The addition of either silica fume or fly ash seemed to have a positive effect even when the DP ratios increased. The reduction of the bond strength due to the incorporation of the DP can be explained by recalling that load transfer between concrete and steel occurs through the action of three mechanisms: chemical adhesion, friction and mechanical interaction of the lugs of the deformed reinforcement 
bearing on the surrounding concrete. For deformed reinforcement, mechanical interaction is the dominant mechanism of response according to $\mathrm{Zhu}$ et al. [23]. The use of the DP as cement replacement seemed to have a softening effect on the matrix, while keeping an adequate chemical adhesion due to the improvement in the ITS as mentioned before. This behavior hindered the development of the mechanical interaction and the bond strength was dominated by the friction resistance. Another parameter contributing to the reduction of the bond strength is the reduced shrinkage of concrete upon cement replacement and consequently the reduced gripping force exert by the concrete as reported by Sonebi et al. [32]. The observed occasional increase in the bond strength for a bigger diameter was reported by Khan et al. [33]. The increase was attributed to the increase in the friction bond component as the bar diameter increased. Also, the inconsistency of bond strength results in SCC mixes has been reported by Zhu [34] and Domone [30] and it was recommended that each concrete mix with a specified composition of the fillers should be tested to evaluate the bond behavior.

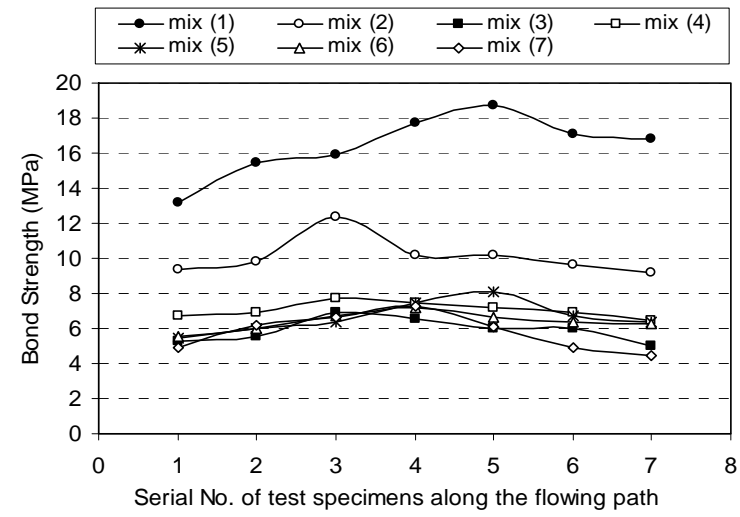

Figure 6. Bond strength along the flowing path (10-mm bar diameter specimens)

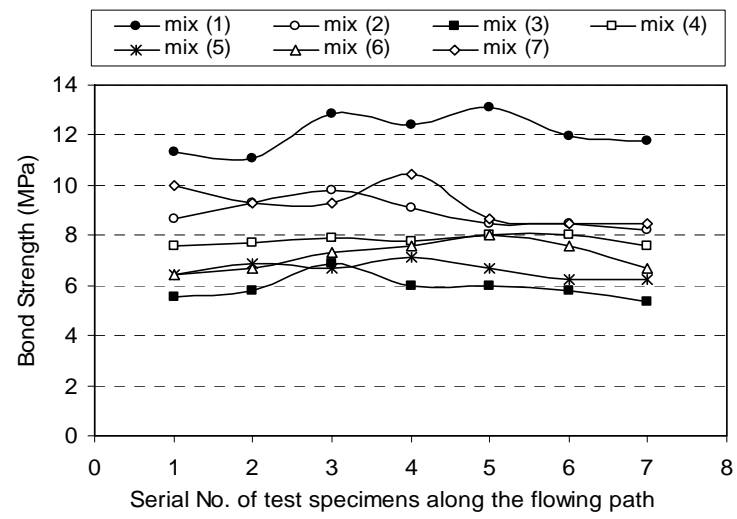

Figure 7. Bond strength along the flowing path (16-mm bar diameter specimens)
Figs. $(6,7)$ shows a plot of the average bond strength for the test specimens along the flow path for the $10 \mathrm{~mm}$ and $16 \mathrm{~mm}$ bars. The specimens were numbered sequentially beginning with the first specimen at the casting end and ending with the seventh specimen at the end of the flow path. It can be seen that the bond strength tended to be higher about the middle of the flow path compared to the strength evaluated at the casting and end points. This trend needs to be further examined in actual size concrete elements being related to size effect and flow characteristics.

\section{CONCLUSIONS}

The current work investigated the potentials of the SCC mixes incorporating dolomite powder along with either silica fume or fly ash to develop bond strength. The variability of bond strength along a flowing path was evaluated, based on the available test results, the following conclusions could be drawn:

1. The bond strength was reduced due to Portland cement replacement with dolomite powder. While the chemical adhesion component was improved, the mechanical interaction was hindered and the bond strength was dominated by the friction resistance.

2. The addition of either silica fume or fly ash positively hindered further degradation of bond strength as the dolomite powder content increased.

3. SCC mixes containing up to $30 \%$ dolomite powder yielded bond strengths that were adequate for design purpose according to the requirements of the ACI 318-08 code.

4. The test results demonstrated inconsistent normalized bond strength in case of the larger steel bar diameter of $16 \mathrm{~mm}$ compared to the 10 $\mathrm{mm}$ steel bar diameter.

5. The bond strength tended to increase about the middle of the flowing path. This trend needs to be further examined in actual size concrete elements being related to size effect and flow characteristics.

\section{REFERENCES}

[1] Ozawa, K., Maekawa, K., Kunishima, M. and Okamura, H. (1989), "High performance concrete based on the durability design of concrete structures", Proceedings East Asia Pacific conference on Structural Engineering (EASEC 2), Chiang Mai, Thailand.

[2] Chan, K.D., Ong, K.C.G. and Tam, C.T. (2010), "Passing ability of SCC - improved method based on the P-Ring", Proceedings of the $35^{\text {th }}$ conference on Our World in Concrete and Structures, Singapore, August, 9 p. 
[3] ACI Committee 232 (2003), "Use of fly ash in concrete", ACI 232.2R-03, $41 \mathrm{p}$.

[4] ACI Committee 234 (2006), "Guide for the use of silica fume in concrete, Bond and development of straight reinforcing bars in tension", ACI 234R-06, $63 \mathrm{p}$.

[5] Dunster, A. (2009), "Silica fume in concrete", BREPress, Watford, UK, 12p.

[6] Kamal, M.M., Safan, M.A., and Al-Gazzar, M.A. (2008), "Blended Portland cements for low-cost self-compacting concrete", Proceedings of the 1st International Conference "New Cements and their Effects on Concrete Performance" National Housing and Building and Research Center (HBRC) and Helwan University, Cairo, Egypt, 14 p.

[7] Al-Gazzar M. A., (2009), Low-cost selfcompacting Concrete, $\mathrm{PhD}$ Thesis, Menoufia University, Egypt, 243p.

[8] Safan, M.A. (2011), "Shear strength of selfcompacting concrete containing different fillers and coarse aggregates", Concrete Research Letters, 2(4), 300-314.

[9] Safan, M.A (2011), "Performance of beams cast with low-cost self-compacting concrete in aggressive environment", Acta Polytechnica, 51(5), 120-130.

[10] ECP 203-2007 (2007), "Egyptian code for the design and construction of reinforced concrete structures", National Building and Research Center (HBRC), Cairo, Egypt, 352 p.

[11] Assié, S., Escadeillas, G., and Waller, V. (2007), "Estimates of self-compacting concrete potential durability", Construction and Building Materials, 21, 1909-1917.

[12] BS 5328-1 (1997), Concrete: Guide to specifying concrete, British Standard Institution, 389 Chiswick High Road, London, W4- 4Al, UK, 32p.

[13] BS 8500 (2002 \& 2006), Concrete: Complementary British Standard to BS EN 2061, Part 1: method of specifying and guidance for the specifier, 66p., and Part 2: Specifications for constituent materials and concrete, British Standards Institution, 389 Chiswick High Road, London, W4- 4Al, UK.

[14] BRE Special Digest-1 (2005), Concrete in aggressive ground, Building Research Establishment (BRE), Watford, UK. Publisher: HIS Rapidoc, Willoughby, Bracknall, Berks, RG12-8DW.

[15] CSA A23.1 (2009), Concrete materials and methods of concrete construction, Canadian Standards Association, Canada, $420 \mathrm{p}$.

[16] Hooton, R.D., Nokken, M.R., and Thomas, M.D.A. (2007), "Portland Limestone Cement: State-of-the-Art Report and Gap Analysis for CSA A3000," Cement Association of Canada
Research and Development, Report SN3053, 59 p.

[17] Thomas, M.., Hooton, D., Cail, K., Smith, B., Wal. J. and Kazanis, K. (2010), "Field trials of concretes produced with Portland limestone cement: New CSA cement type performs well in an aggressive environment", Concrete International, 32(1), 35-41

[18] ACI Committee 408 (2003). "Bond and development of straight reinforcing bars in tension", ACI 408R-03, 49 p.

[19] FIB Bulletin 10 (2000), "Bond of reinforcement in concrete", State-of-the-art Report, FIB Bulletin 10, Switzerland, 427p.

[20] De Almeida F.M., De Nardin, S. and El-Debs, A.L.H.C. (2005), "Evaluation of the bond strength of self-compacting concrete in pull-out tests", Proceedings of the $2^{\text {nd }}$ North American conference on the Design and Use of SelfConsolidating Concrete and $4^{\text {th }}$ International RILEM Symposium on Self-Compacting Concrete. Chicago, pp. 44-55.

[21] Chan, Y.W., Chen, Y.S. and Liu, Y.S. (2003), "Development of bond strength of reinforcing steel in self-consolidation concrete", ACI Structure Journal, 100(4), 490-498.

[22] Daoud, A., Lorrain, M. and Laborderie, C. (2003), "Anchorage and cracking behavior of self-compacting concrete", Proceedings of third RILEM International Symposium on SelfCompacting Concrete, Wallevik, O. and Nielsson, I. Editors, Reykjavik Iceland, RILEM Publications, PRO 33, Bagneux, France.

[23] Zhu, W., Sonebi, M., Bartos, P.J.M. (2004), "Bond and interfacial properties of reinforcement in self- compacting concrete", Materials and Structures 37, 442-448.

[24] Turk, K., Karatas, M. and Ulucan, Z. (2010), "Effect of the use of different types and dosages of mineral additions on the bond strength of lapspliced bars in self-compacting concrete", Materials an Structures, 43, 557-570.

[25] BS-EN 197-1 (2000), Cement: composition, specifications, and conformity criteria for common cements, British Standard Institution, 389 Chiswick High Road, London, W4- 4Al, UK, $52 \mathrm{p}$.

[26] ASTM C618 (2000), "Specification for fly ash and raw calcined natural pozzolan for use as a mineral admixture in Portland cement concrete", Annual Book for ASTM Standards, 4, 4 p.

[27] ASTM C494 (1999) "Standard specification for chemical admixtures for concrete" $9 \mathrm{p}$.

[28] Foroughi-Asl A., Dilmaghani, S. and Famili, H. (2008), "Bond strength of reinforcement steel in self-compacting concrete", International Journal of Civil Engineering, 6(1), 24-33. 
[29] ACI 318R-08 (2008), "Building Code Requirements for structural concrete (318-08) and commentary", ACI Committee $318,471 \mathrm{p}$.

[30] Domone, P. L. (2007), "A Review of the Hardened Mechanical Properties of Selfcompacting Concrete", Cement and Concrete Composites, 29, 1-12.

[31] Menezes, F., El Debs, M.K and El Debs, A.L. (2008), "Bond-slip behavior of self-compacting concrete and vibrated concrete using pull-out and beam tests", Materials and Structures, 41, 1073-1089.

[32] Sonebi, M. and Bartos, P.J.M. (1999), "Hardened SCC and its bond with reinforcement", Proceedings of the First International RILEM Symposium on "Selfcompacting concrete", Skarendahl, A. and Petersson, O. Editors.

[33] Khan, M.S., Reddy, A.R., Shariq, M. and Prasad, J. (2007), "Studies in bond strength in RC flexural members", Asian Journal of Civil Engineering (Building and Housing), 8(1), 8996

[34] Zhu, W., Gibbs, J.C., Bartos, P.J.M. (2001), "Uniformity of in situ properties of selfcompacting concrete in full-scale structural elements", Cement and Concrete Composites, 23(1), 57-64. 